\title{
120. The Heart Succinic Dehydrogenase Reducing Substance in the Urines of Malignant Diseases
}

\author{
By Satosu NaKagAwa \\ Second Medical Clinic, Medical Faculty, Hokkaido University, \\ Sapporo \\ (Comm. by T. Furuhata, M.J.A., Nov. 12, 1953)
}

The most likely diagnostic key for cancer should be found in a study of the metabolism of cancer tissues. It is possible that there are abnormal metabolic substances liberated from cancer cells which would enter into the circulating blood and finally be excreted in the urine. With this in mind a study of the urines of patients with malignant diseases was begun ten years ago at the Second Medical Clinic, Hokkaido University Hospital, and I have reported in a previous paper, the liver catalase reducing factor in the urines of patients with malignant tumors.

A high concentration of lactic acid in cancer tissues was reported as compared with homologous tissues. Undoubtedly, this accumulation of lactic acid in tumor tissues was associated with the high rate of glycolysis in malignant tissues; but, since so little lactate was removed by oxidative processes, an impairment of enzyme system was suggested. Elliot, Benoy, and Baker reported that the ability of tumor tissue to oxidize succinate to fumarate, appeared to be defective. Numerous papers appeared describing succinic dehydrogenase activity of various tissues and reporting diminished activity of the enzyme in tumor tissues.

I have reported in the previous papers, the liver catalase reducing factor in the urines and body fluids of cancerous patient, and the liver arginase reducing factor in tumor tissue and in the urines of patients with cancer. In connection with thos experiments, my assistant $\mathrm{H}$. Majima tried in this experiment to find a substance in the urines of cancerous patients which would cause the reduction of the heart succinic dehydrogenase activity of experimental animals.

\section{Experimental}

1) Experimental animals :

Mice of both sexes of Swiss strain were used, except tumorbəaring rats. For tumor-bearing animals, rats of Gifu strain were used. All animals were maintained on a standard diet.

2) Preparation of urine extract:

The urines which were employed in this work were collected 
from inpatients of the Hokkaido University Hospital who were diagnosed as having malignant tumor or not by either clinical or histological examination.

The urine extracts which were called "crude extract", were prepared in the way, just as reported in the previous paper, and a volume equivalent to $100 \mathrm{ml}$ of urine sample was injected into the peritoneal cavity of a mouse. After 24 hours the animals were killed by decapitation and the heart dehydrogenase activity was immediately measured.

3) Method of the heart succinic dehydrogenase activity estimation :

The animal was killed by decapitation, and the heart was immediately removed. This heart was weighed on an analytical balance and then ground with washed and ignited sand in a motor. $2 \mathrm{ml}$ of phosphate buffer solution ( $\mathrm{pH} 7.4$ ) for $100 \mathrm{mg}$ of heart were added. This mixture was placed in a centrifuge tube, stirred well, and then centrifuged at 2,000 r.p.m. for 5 minutes. The supernatant was removed and tested immediately for its ability to decolorize methylene blue anaerobically according to the Thunberg technic.

In measuring the dehydrogenase activity, $0.5 \mathrm{ml}$ of $\mathrm{M} / 2$ sodium succinate aqueous solution was placed in the stopper of the Thunberg tube. Into the tube proper the following reagents were introduced: $0.4 \mathrm{ml}$ of the above-mentioned tissue extract, $0.5 \mathrm{ml}$ of a 1:5000 methylene blue solution and $1.5 \mathrm{ml}$ of phosphate buffer $(\mathrm{pH} \mathrm{7.4)}$. The tube was evacuated with gentle agitation till at about $12 \mathrm{~mm}$ $\mathrm{Hg}$, and then placed in a water bath for 5 minutes in order to bring to $37.0 \mathrm{C}$. The sodium succinate aqueous solution was then tilted into the enzyme containing tube proper and the decolorization time determined visually. The enzyme activity was arbitrarily expressed as minutes ${ }^{-1} \times 10^{2}$.

\section{Results}

1) The heart succinic dehydrogenase activity of normal rats : The heart succinic dehydrogenase activity of 8 normal rats varied from 6.3 to 7.6 with an average of 7.0 .

2) The heart succinic dehydrogenase activity of tumor-bearing rats :

The rats used in this phase of the experiment all had successful intraperitoneal implantation of Yoshida (ascites) sarcoma. The succinic dehydrogenase activity was measured at periodical intervals after implantation. There was almost no change in succinic dehydrogenase activity until 3 days after implantation, then a marked 
dccrease was noted, which continued until they died of the disease after about 10 days. This data confirmed the results of many observers on tumor-bearing animals.

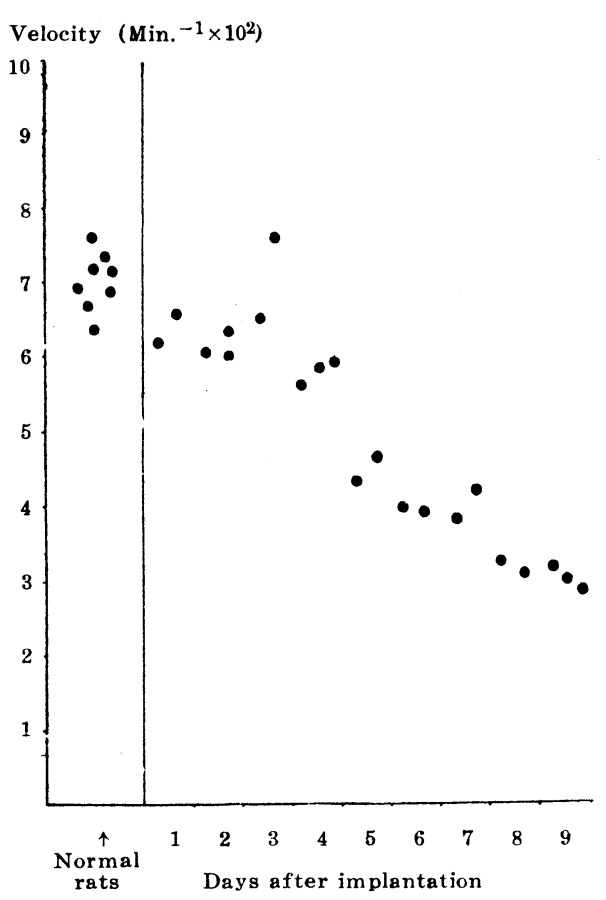

Fig. 1. The heart succinic dehydrogenase activity of normal and Yoshida sarcoma implanted Gifu strain rats
3) The heart succinic dehydrogenase activity of normal mice :

The heart succinic dehydrogenase activity of 24 normal mice varied from 9.5 to 14.8 with an average of $11.5 \pm 0.35$.

4) Control examinations :

Urine extracts from normal individuals and from patients suffering from non-malignant diseases were injected into 42 mice. There was no decrease in the heart succinic dehydrogenase activity including 3 normal individuals and 2 pregnant women. Similar results were obtained with extracts from 30 patients with benign tumors, various infections and metabolic diseases. In several of these diseases, determinations were made in varied stages of the diseases. The activity varied from 9.1 to 15.4 , the mean figure being $11.0 \pm 0.43$, which was not significantly different from $11.5 \pm 0.35$ found in normal mice.

5) The heart succinic dehydrogenase activity of mice injected with urine extracts of cancerous patients:

The urine extracts of 43 cancerous patients were inoculated into 66 mice. The heart succinic dehydrogenase activity was 4.4-8.5 in all but 7 cases. 3 of these 7 cases were patients with endometral adenocarcinoma who had shown clinical improvement after large dosage of $\mathrm{X}$-ray and radium irradiation. Another 2 cases were small uterine carcinoma (grade I). In contrast to these cases, 6 of uterine carcinoma with metastasis showed definite decrease in the dehydrogenase activity. The remaining 2 cases, a stomach cancer and a pancreas cancer revealed no decrease which would probably be caused by technical error. The mean figure was $7.4 \pm 0.24$ which represented a $35 \%$ decrease compared with 
$11.5 \pm 0.35$, the mean figure of the normal mice.

6) The heart succinic dehydrogenase activity of mice injected with urine extracts of sarcoma patients :

The urine extracts of 3 sarcoma patients were inoculated into 3 mice. The heart succinic dehydrogenase activity revealed $6.4 \pm 0.06$, a significant decrease compared with the controls.

7) The heart succinic dehydrogenase activity of mice injected with urine extracts of leukemia patients:

Mice were injected with urine extracts of 4 cases of acute leukemia and 3 cases of chronic leukemia patients. The moderate decrease of the heart succinic dehydrogenase activity was demonstrated in 4 cases of acute leukemia and 1 case of exacerbation of chronic leukemia, but not in chronic leukemia. The mean figure was $9.2 \pm 0.76$.

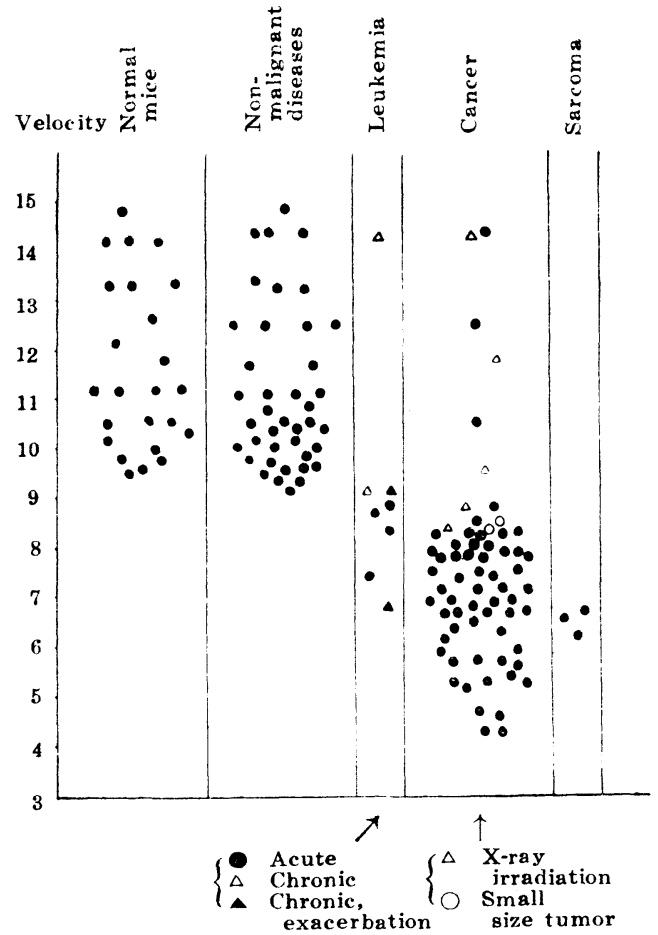

Fig. 2. Heart succinic dehydrogenase activity of mice injected with urine extracts

8) Studies were done to determine the physical nature of the active crude urine extracts from cancerous patients and the following data were noted:

(1) The urine extracts could be preserved as powder for 30 days at room temperature without loss of activity.

(2) The activity was not affected by heating at $100^{\circ} \mathrm{C}$ for 30 minutes in the medium of $\mathrm{pH} 1.2$, 7.0 and 12.5 respectively.

(3) The activity remained the same after storage for 48 hours in an ice-box $\left(4.0^{\circ} \mathrm{C}\right)$ in the medium of $\mathrm{pH} 1.2,7.0$

and 12.5 respectively.

(4) The active factor was not dialysable by 48 hours dialysis.

(5) The active substance was not soluble in alcohol-ether after 48 hours treatment in an ice-box $\left(4.0^{\circ} \mathrm{C}\right)$, and the activity in the residue remained the same.

(6) The activity was completely destroyed in aqueous solution by $1,200 r$ X-ray irradiation. 
(7) The activity had resistance to ultra-violet treatment (for 30 minutes, distance $10 \mathrm{~cm})$.

\begin{tabular}{l|r|r|r|r|r}
\hline & $\begin{array}{c}\text { Number of } \\
\text { examinations }\end{array}$ & $\begin{array}{r}\text { Decolorization time } \\
\text { (Min.) }\end{array}$ & \multicolumn{2}{|c}{ Velocity } \\
\cline { 3 - 5 } & Mean & Range & (Min.-1 $\left.\times 10^{2}\right)$ & S $x$ \\
\hline Normal & 24 & 8.7 & $6.7-10.5$ & 11.5 & 0.35 \\
Control & 42 & 9.1 & $6.5-11.0$ & 11.0 & 0.43 \\
Cancer & 66 & 13.5 & $7.0-23.5$ & 7.4 & 0.24 \\
Sarcoma & 3 & 15.5 & $15.0-16.0$ & 6.4 & 0.06 \\
Leukemia & 8 & 10.9 & $7.0-15.0$ & 9.2 & 0.76
\end{tabular}

\section{Discussion}

The results of this present work indicated that some very definite, clear cut change took place in the heart succinic dehydrogenase activity after intraperitoneal implantation of Yoshida sarcoma in rats, and similar phenomenon could be occurred by injection of the urines of malignant diseases into mice. This change probably reflects some metabolic alternations in the biochemistry of tumor tissues.

The urine extracts which showed no decrease of the succinic dehydrogenase activity were originated from cancerous patients, who had undergone to strong irradiation treatment. This would probably be caused by either destruction of the succinic dehydrogenase reducing factor in the tumor tissue or its decreased liberation from cancer tissue.

A few cases of leukemia patients revealed some decrease of the heart succinic dehydrogenase activity, especially in acute cases. This is a very interesting fact, however, because number of examinations were too small to conclude; we have to wait until many cases were assayed.

\section{Summary}

1) In Yoshida (ascites) sarcoma implanted rats, there was almost no change in succinic dehydrogenase activity until 3 days after implantation, then a marked decrease was noted, which continued until they died of the disease after about 10 days.

2) A "succinic dehydrogenase reducing substance" which, when injected into the peritoneal cavity of experimental animals would reduce the heart succinic dehydrogenase activity, could easily be demonstrated in the urines of patients with cancer and sarcoma, 
independent of their site, but not in cases of benign diseases.

3) This substance was missed often in the urines of patients with malignant diseases who had undergone to vigorous irradiation treatment.

4) The urine extracts of very small malignant tumor, showed no decrease of the heart succinic dehydrogenase activity.

5) In a few cases of leukemia, especially acute ones, the urine extracts revealed the decrease of the heart succinic dehydrogenase activity, when injected into mice.

6) The succinic dehydrogenase reducing factor is stable for 30 days in room temperature as powder, heatresistant by testing at $100^{\circ} \mathrm{C}$ for 30 minutes, non-soluble in alcohol-ether mixture, nondialysable, destroyed by strong X-ray irradiation, but resistant to ultra-violet treatment.

\section{References}

1) Greenstein, J.P.: Biochemistry of Cancer, New York (1947).

2) Nakagawa, S.: Proc. Japan Acad., 28, 305 (1952).

3) Nakahara, W. and Fukuoka, F.: Jap. Med. Journ., 1, $271(1948)$.

4) Elliot, K. A., Benoy, M. P., and Baker, Z. : Biochem. J., 29, 1937 (1935).

5) Schneider, W. C. and Potter, V. R. : Cancer Research, 3, 353 (1943).

6) Potter, V. R. : Advance in Enzymology, 4 (1944).

7) Majima, H.: J. Hokkaido Med. Ass. (in Jap.) (in press). 